\title{
Evaluation of Competitiveness of Power Enterprises Based on the Entropy Method
}

\author{
Yan Lin, Xiao-juan Tang \\ Department of Accounting ,Hebei Finance University, Baoding, 071000, China
}

Keywords: Power enterprises; Entropy method; Improved TOPSIS; Competitiveness evaluation

\begin{abstract}
With the gradual reform of power system and the strong competition of power enterprises, it is extremely important to analyze the enterprise competitiveness accurately. Thus a tool is urgently needed to evaluate the competitiveness of power enterprises effectively. Combined with entropy method and an improved TOPSIS method, an effective evaluation model of power enterprise competitiveness is constructed, which can overcome the weakness of the traditional TOPSIS method, greatly reduce the calculation amount when alternatives change, and ensure the applicability of this model. Finally, the model is applied in the competitiveness evaluation of power enterprises. It can accurately assess the competitiveness of power enterprises, provide the reference for the subsequent project decision, and verify its rationality and validity.
\end{abstract}

\section{Introduction}

With the development of the power system reform, the competition between power enterprises becomes increasingly fierce. Moreover, the energy prices of power industry directly affect the production cost of related industries [1]. Therefore, it is vitally important to correctly evaluate the competitiveness of power enterprises, which affects the operating efficiency of state-owned assets and competitiveness of related industrial enterprises. So an effective tool for the enterprise competitiveness evaluation is urgently needed. It is practically significant to establish a suitable model and make a reasonable effective evaluation for competitiveness of power enterprises, which can not only comprehensively analyze the competition level of related power enterprises, but also provide a basis for subsequent planning decisions.

Scholars have carried out some relevant researches on enterprise competitiveness evaluation [2-3]. Most of them focused on the general enterprise competitiveness, few studied specific sub-sectors or sub-regions enterprise competitiveness. In addition, about the evaluation models, gray correlation analysis method, analytic hierarchy process and the fuzzy comprehensive evaluation method were focused on. So it lacks of an easy-calculated, reliable and quantitative model to evaluate the enterprise competitiveness and then make a reasonable decision.

Based on the above factors and relevant literature, combined with the characteristics of power generation enterprises, a more comprehensive enterprise competitiveness evaluation index system is built. Moreover, the index weight is determined by entropy method and the competitiveness evaluation model is established by improved TOPSIS method. Which can both overcome the weakness of the reversed order resulted from the traditional TOPSIS method, and can reduce the calculation amount greatly when the alternatives change [4].so it ensures its applicability in the competitiveness evaluation of power enterprises. At last, apply the evaluation model to empirical analysis in order to provide useful references for the subsequent researches in this field.

\section{The evaluation index system of power enterprise competitiveness}

According to the competitiveness status and characteristics of power enterprises, considering the economic, social and environmental benefits of power enterprises, and following the comparable, scientific and comprehensive principles of index selection, this paper selects the potential competitiveness, scale competitiveness, enterprise development ability, sales and cost competitiveness, enterprises operating ability, enterprise market share and safe and reliable ability seven aspects as the main indexes[5-6], as well as establishes a reasonable and comprehensive 
competitiveness evaluation index system of power enterprises. Specific indexes are shown in Table 1 .

Table 1: Competitiveness evaluation index system of power enterprises

\begin{tabular}{|c|c|c|}
\hline & One class index & Two class index \\
\hline \multirow{18}{*}{ 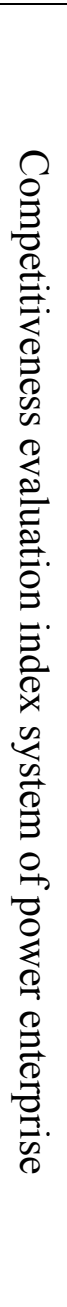 } & \multirow{3}{*}{$\begin{array}{c}\text { potential } \\
\text { competitiveness(A) }\end{array}$} & competitiveness of institutional basis \\
\hline & & competitiveness of human resources \\
\hline & & competitiveness of resource technologies \\
\hline & \multirow{3}{*}{ scale competitiveness(B) } & average unit capacity \\
\hline & & the per capita rate of equipment \\
\hline & & total equity \\
\hline & \multirow{3}{*}{ development ability $(\mathrm{C})$} & the average growth rate of assets \\
\hline & & the average growth rate of sales \\
\hline & & the average growth rate of net profits \\
\hline & \multirow{3}{*}{$\begin{array}{l}\text { sales and cost } \\
\text { competitiveness(D) }\end{array}$} & the average feed-in tariff \\
\hline & & per kilowatt installed generating capacity \\
\hline & & the unit cost of power generation \\
\hline & \multirow[b]{2}{*}{ operating ability(E) } & the turnover of total assets \\
\hline & & return rates of total assets \\
\hline & \multirow[b]{2}{*}{ market share $(\mathrm{F})$} & market shares \\
\hline & & $\begin{array}{l}\text { annual average utilization hours of power generation } \\
\text { equipments }\end{array}$ \\
\hline & \multirow{2}{*}{$\begin{array}{l}\text { safe and reliable } \\
\text { ability }(\mathrm{G})\end{array}$} & equivalent available factor \\
\hline & & unplanned outage times \\
\hline
\end{tabular}

Among them, the institutional basis competitiveness reflects the features of power generation enterprises in corporate governances and management systems; Human resources competitiveness decides whether it has good human resource reserves; Resource technology competitiveness may indicate its geographical resources, relationship resources and related power generation. The average unit capacity and per capita equipment rate, as well as the total equity can directly reflect the scale competitiveness of power enterprises. And their development abilities are decided by the average growth rate of assets, the average growth rate of sales and the average growth rate of net profits. The average feed-in tariff and per kilowatt installed generating capacity may reflect sales competitiveness of power enterprises to some extent; the unit cost of power generation decides its cost competitiveness. Operating abilities of power generation enterprises determine whether they can be in the long-term market competition reflected by the total asset turnover rates and the total asset return rates. To a certain degree, the enterprise market shares are on behalf of their viabilities, represented by market shares and annual average utilization hours of power generation equipments. The safe and reliable ability is the foundation to ensure the competitiveness of power enterprises, reflected by equivalent available factor and unplanned outage times. 


\section{Establish the evaluation model}

\section{The improvement and selection of modeling methods}

It is so crucial about every step in the comprehensive evaluation, and for each step choosing different ways will obtain different conclusions [7]. So, based on the power enterprise competitiveness evaluation index system established above and the actual characteristics of power enterprises, the standardized processing method and TOPSIS method were improved. In view of the vast majority of indexes are quantitative, the index weight was determined by entropy method. Ultimately, the competitiveness of power enterprises was evaluated in order to obtain an accurate and objective result.

For the multi-objective decision-making, the indexes' standardized processing is the basis [8]. Traditional standardized methods may bring the reversed order [9], so the standardization method of ideal point expected by decision-makers is put forward to eliminate the phenomenon. Under the condition of decision-makers' subjective preferences, the negative ideal point and the positive ideal point separately refers to the virtual worst value and virtual best value for each index, represented by $a_{j}^{-}$and $a_{j}^{+}$. The improved standardized method can keep the independence of each project. The specific implementation process is in the section2.2.

Entropy method is a quantitative method and according the information amounts contained in each index to determine the weight. Supposing there are $n$ participating projects and each has $m$ evaluation indexes. $x_{i j}$ is the value of the participating project $i$ and the evaluation index $j$.Therefore, the entropy of the index $j$ is:

$$
e_{j}=-\frac{1}{\ln n} \sum_{i=1}^{n} p_{i j} \ln p_{i j}, \quad p_{i j}=\frac{x_{i j}}{\sum_{i=1}^{n} x_{i j}}
$$

$p_{i j}$ stands for the proportion. The larger the entropy value, the smaller the difference. Namely the weight is smaller, and vice versa. As a result, based on most indexes of power enterprise competitiveness are quantitative, entropy method is chosen to determine the weights.

According to the distances from each project to the negative and positive ideal point, TOPSIS method decides the relative closeness degree. Considering the actual characteristics of power enterprises, this paper put forward an improved TOPSIS method which uses the absolute positive and negative ideal point to replace the original positive and negative ideal point, aiming to keep orders and evaluate the competitiveness of power enterprises efficiently and objectively.

\section{The evaluation steps of power enterprise competitiveness}

(1) Build the index matrix

There are $n$ participating projects and each project has $m$ indexes. $x_{i j}$ is the value of the participating project $i$ and the evaluation index $j$. The original matrix is $X=\left(x_{i j}\right)_{n \times m}$ $X=\left(\begin{array}{ccc}x_{11} & \cdots & x_{1 m} \\ \vdots & \ddots & \vdots \\ x_{n 1} & \cdots & x_{n m}\end{array}\right)$

(2) The standardization of index matrix

On the basis of the improved range variation method proposed above to standardize and get a dimensionless matrix: $Y=\left(y_{i j}\right)_{n \times m}$

The efficiency indexes: $y_{i j}=\frac{x_{i j}-a_{j}^{-}}{a_{j}^{+}-a_{j}^{-}}$ 
The cost indexes: $y_{i j}=\frac{a_{j}^{+}-x_{i j}}{a_{j}^{+}-a_{j}^{-}}$

Where, ${ }^{a_{j}^{-}}$is the absolute negative ideal point and $a_{j}^{+}$is the absolute positive ideal point.

(3) The determination of index weights

Use the entropy method mentioned above to obtain the index weights. Firstly, use the following formula to calculate the proportion $p_{i j}$ :

$$
p_{i j}=\frac{y_{i j}}{\sum_{i=1}^{n} y_{i j}}
$$

Secondly, calculate the entropy value of index $j$ :

$$
e_{j}=-\frac{1}{\ln n} \sum_{i=1}^{n} p_{i j} \ln p_{i j}
$$

Thirdly, count the variance coefficient of index $j$ :

$$
g_{i}=1-e_{j}
$$

Where, $0 \leq g_{j} \leq 1$

Finally, calculate the weight of index $j$ :

$$
\omega_{j}=\frac{g_{j}}{m-E_{e}}, \quad E_{e}=\sum_{j=1}^{m} e_{j}
$$

Where, $0 \leq \omega_{j} \leq 1, \sum \omega_{j}=1$

(4) The weighting and standardization of index matrix

Multiply the normalized index matrix by the corresponding weights to get the matrix R:

$R=\left(r_{i j}\right)_{n \times m}=\left(\omega_{j} y_{i j}\right)_{n \times m}$

(5) Calculate the distances

We can get the standardized absolute positive and negative ideal point from (1)-(4):

$$
\begin{gathered}
A^{*}=\left(\begin{array}{llll}
\omega_{1} & \omega_{2} & \cdots & \omega_{m}
\end{array}\right) \\
A^{-}=\left(\begin{array}{llll}
0 & 0 & \cdots & 0
\end{array}\right)
\end{gathered}
$$

Then the Euclidean distances from each project to the absolute positive and negative ideal point are:

$$
\begin{aligned}
& d_{i}^{*}=\left[\sum_{j=1}^{m}\left(r_{i j}-\omega_{j}\right)^{2}\right]^{\frac{1}{2}} \\
& d_{i}^{-}=\left[\sum_{j=1}^{m}\left(r_{i j}-0\right)^{2}\right]^{\frac{1}{2}}
\end{aligned}
$$

Where, $\mathrm{i}=1,2 \ldots \mathrm{n}$

(6) Calculate the relative closeness degree $c_{i}^{*}=d_{i}^{-} /\left(d_{i}^{-}+d_{i}^{*}\right) c_{i}^{*}=d_{i}^{-} /\left(d_{i}^{-}+d_{i}^{*}\right)$

(7) The rank of all projects.

All projects are ranked by their relative closeness. If the $c_{i}^{*}$ is bigger, the competitiveness of corresponding power enterprise will be higher; If the $c^{c_{i}^{*}}$ is smaller, the competitiveness of corresponding power enterprise will be lower. 


\section{Example analyses}

\section{Build the weighting and standardized index matrix}

Five power companies which have been listed are as our empirical study objects, including one quantitative index: potential competitiveness of enterprises and six qualitative indexes: scale competitiveness, development ability, sales and cost competitiveness, operating ability, market share and safe and reliable ability of enterprises. Through the questionnaire and combining with the characteristics of the qualitative index, relevant experts use 0-1 scoring method to obtain the enterprises' potential competitiveness. Moreover, the quantitative indexes are standardized according to the formula (2). Hence, the consolidated competitiveness data results of five power companies in seven indexes are showed in Table 2.

Table 2: Competitiveness scoring results of power enterprise

\begin{tabular}{cccccccc}
\hline projects & $\mathrm{A}$ & $\mathrm{B}$ & $\mathrm{C}$ & $\mathrm{D}$ & $\mathrm{E}$ & $\mathrm{F}$ & $\mathrm{G}$ \\
\hline 1 & 0.40 & 0.80 & 0.80 & 0.60 & 0.80 & 1.00 & 0.40 \\
2 & 0.40 & 0.60 & 1.00 & 0.40 & 0.80 & 0.40 & 0.20 \\
3 & 0.40 & 0.80 & 1.00 & 0.40 & 0.80 & 0.80 & 0.20 \\
4 & 0.20 & 0.40 & 0.20 & 0.60 & 0.20 & 0.60 & 0.40 \\
5 & 0.20 & 0.40 & 0.20 & 0.20 & 0.20 & 0.60 & 0.20 \\
\hline
\end{tabular}

Use the entropy method and the formula (3) - (7) to determine each index' weight. The results are shown in table 3.

Table 3: Index weights

\begin{tabular}{cccccccc}
\hline projects & $\mathrm{A}$ & $\mathrm{B}$ & $\mathrm{C}$ & $\mathrm{D}$ & $\mathrm{E}$ & $\mathrm{F}$ & $\mathrm{G}$ \\
\multirow{2}{*}{ weights } & 0.139 & 0.142 & 0.137 & 0.143 & 0.138 & 0.150 & 0.147 \\
& 8 & 5 & 9 & 8 & 5 & 2 & 3 \\
\hline
\end{tabular}

According to the formula (8) and above weights to get the standardize index matrix R:

$\left[\begin{array}{lllllll}0.0559 & 0.1140 & 0.1103 & 0.0863 & 0.1108 & 0.1502 & 0.0587 \\ 0.0559 & 0.0855 & 0.1379 & 0.0575 & 0.1108 & 0.0601 & 0.0295 \\ 0.0559 & 0.1140 & 0.1379 & 0.0575 & 0.1108 & 0.1202 & 0.0295 \\ 0.0280 & 0.0567 & 0.0276 & 0.0863 & 0.0277 & 0.0901 & 0.0589 \\ 0.0280 & 0.0570 & 0.0276 & 0.0288 & 0.0277 & 0.0901 & 0.0295\end{array}\right]$

\section{Calculation of the Euclidean distance}

According to the above contents, we can get the absolute positive ideal point, namely, the weight, and the absolute negative ideal point, shown in Table 4.

Table 4: Calculation results

\begin{tabular}{cccccccc}
\hline & $\mathrm{A}$ & $\mathrm{B}$ & $\mathrm{C}$ & $\mathrm{D}$ & $\mathrm{E}$ & $\mathrm{F}$ & $\mathrm{G}$ \\
\hline positive & 0.13975 & 0.14248 & 0.13788 & 0.14380 & 0.13850 & 0.15024 & 0.14734 \\
negative & 0 & 0 & 0 & 0 & 0 & 0 & 0 \\
\hline
\end{tabular}
5 .

Based on the Table 4 and formula (9) - (10), the Euclidean distances are got and shown in Table

Table 5: Euclidean distance

\begin{tabular}{ccc}
\hline projects & $\begin{array}{c}\text { the Euclidean distances to the } \\
\text { absolute positive ideal point }\end{array}$ & $\begin{array}{c}\text { the Euclidean distances to the } \\
\text { absolute negative ideal point }\end{array}$ \\
\hline 1 & 0.14316 & 0.27213 \\
2 & 0.20128 & 0.22251 \\
3 & 0.17565 & 0.25670 \\
4 & 0.24287 & 0.15685 \\
5 & 0.27385 & 0.12401 \\
\hline
\end{tabular}

\section{Calculate the relative closeness degree and rank all projects}

According to Table 5 and formula (11) ,Calculate the relative closeness degree of each project, shown in Table 6. 
Table 6: The relative correlation degree

\begin{tabular}{cccccc}
\hline projects & 1 & 2 & 3 & 4 & 5 \\
\hline the relative closeness degree & 0.6553 & 0.5251 & 0.5940 & 0.3924 & 0.3117 \\
\hline
\end{tabular}

Seen from Table 6 , the relative closeness degree of evaluated power generation enterprise competitiveness is: $1>3>2>4>5$. Because the project far from the absolute negative ideal point and closer to the absolute positive ideal point is better, the project owing higher relative closeness degree is better. In projects $1-5$, the project 1 is highest, indicating the first enterprise' competitiveness is largest; the project 5 is lowest, indicating the fifth enterprise' competitiveness is least.

\section{Conclusions}

It is of practical significance to evaluate the competitiveness of power enterprises. Two aspects were focused on in this paper: on one hand, based on the actual characteristics of power enterprises, a more comprehensive evaluation index system included 7 main indexes and 17 small indexes was set up. On the other hand, combined with power enterprises' practical considerations and entropy method, build an applicative evaluation model of power enterprise competitiveness, which can accurately assess power enterprise competitiveness, verify its validity and rationality, and provide references for the late project decision.

\section{References}

[1] LI Hong-ze, HE Hai-feng, GUO Xin. Evaluation of independent generation's competition competence after separation of grid and generation [J]. Power System Technology, 2004, 28(20): 7-10.

[2] GUAN Lei, NIU Dong-xiao. Application of improved entropy TOPSIS to evaluation of competitive performance of power companies[J]. East China Electric Power, 2008, 36(5): 10-13.

[3] CHEN Li-rong, GUO Ji-wei, WANG Jing-min. Application of the gray relevant analysis based on entropy in evaluating competition of power enterprises[J]. Journal of Electric Power, 2005, 20(4): 359-361

[4] ZHANG Yan. Research on comprehensive evaluation methods of enterprise competitiveness[J]. Commercial Research, 2006, 10(4): 65-68.

[5] WANG Jing-min, SUN Yan-fu, KANG Jun-jie. Evaluation of competitive of power enterprises based on entropy and improved TOPSIS [J]. Journal of North China Electric Power University, 2010, 37(6):61-64.

[6] ZHANG Li-hui, QI Jian-xun, TAN Zhong-fu. Research on evaluation model of competitiveness of generation enterprises in this context of reform of power market $[\mathrm{J}]$. China Management Science, 2006, ( 14): 637-642

[7] HU Yong-hong, HE Si-hui. Method of comprehensive evaluation [M]. Beijing: Science Press, 2000

[8] LI Wei, WANG Jing, NIU Dong-xiao. Competitive ability evaluation for generation enterprises based on combinational weight $[\mathrm{J}]$. Journal of North China Electric Power University, 2006,33(5):93-96.

[9] LI Yuan-yuan, ZHOU Guo-hua, HAN Jiao-jie. Application in the evaluation of multi-project priorities based on Entropy and improved TOPSIS method [J]. Statistics and Decision, 2008, 33(14):159-160 